Functional studies dealing with insulin and B-adrenergic receptors were hampered by huge individual variations and additional studies need to be performed.

Enzyme studies revealed that $5^{\prime}$ nucleotidase (EC 3.1.3.5) activity did not seem to be modified by diet and castration but was always higher in $S$ than in $P(-3$-fold $)$. Adenylate cyclase (EC 4.6.1.1) stimulation by various effectors increased when animals were fed the sunflower diet. Dietary effect was much more pronounced when stimulation was nearer the catalytic subunit. There was no significant tissue effect with the control diet, but stimulation became higher in $\mathrm{P}$ than in $\mathrm{S}$ with the sunflower diet.

Genetic relationships between fat androstenone level in males and development of male and female genital tract in pigs. $P$. Sellier $1, M$. Bonneau 2 and J. Gruand 3 (1 INRA, Station de Génétique quantitative et appliquée, 78350 Jouy-en-Josas, 2 INRA, Station de Recherches porcines, Saint-Gilles, 35590 L'Hermitage, and 3 INRA, Station Expérimentale de Sélection Porcine, 86480 Rouille, France)

A single-generation selection experiment was undertaken to assess to what extent fat androstenone level in boars can be reduced by breeding while maintaining normal sexual development in boars and gilts. In Large White boars of around $114 \mathrm{~kg}$ live weight, the androstenone level was determined on a biopsy of fat taken in the neck region and testes size was estimated by an index combining live measurements of testes width and scrotal area. Three groups of boars (4 per group) were kept for breeding : (1) group $S$ ('small') exhibiting low fat androstenone level (intensity of selection $i=-1.50$ units of phenotypic standard deviation) and small testes size $(i=-2.74)$; group $\mathrm{L}$ ('large') exhibiting low fat androstenone level $(i=-1.32)$ and large testes size $(i=+0.50)$, and (3) group C ('control'). Records for fat androstenone level and testes size at $104 \mathrm{~kg}$ live weight and development of genital tract at slaughter (124 $\mathrm{kg}$ live weight) were collected on 225 male offspring from these boars. In addition, proportion of puberal gilts and development of genital tract at slaughter (124 kg live weight) were recorded on 187 female offspring. The response to selection 'against' fat androstenone level was significant $(P<0.01)$ in both groups $S$ and $L$. Of particular interest is that $a$ normal development of testes and bulbourethral glands was preserved in offspring from $\mathrm{L}$ sires, at least at $124 \mathrm{~kg}$ live weight, though they exhibited a large decrease $(P<0.01)$ in fat androstenone level at the usual slaughter weight of $104 \mathrm{~kg}$. However, a strong delay in puberty $(P<0.01)$ was found in gilts from both groups S and L: only $35-37 \%$ of those gilts had reached puberty at $124 \mathrm{~kg}$ live weight, as compared to $79 \%$ in the 'control' group. Realized genetic parameters for fat androstenone level and testes size were derived from 'index-in-retrospect' coefficients and selection responses in $S$ and $L$ groups. Estimates of realized heritability were 0.88 for fat androstenone level and 0.49 for testes size. The estimate of realized genetic correlation between the two traits was positive (around 0.55), indicating that decreasing fat androstenone content and increasing testes size are genetically antagonistic.

\section{Influence of the degree of lipid} unsaturation on sensory properties of minced meat products. C. Touraille and J.P. Girard (Station de recherches sur la viande, INRA, Theix 63122 Ceyrat, France)

Large White pigs were fed with 4 different diets based on : 1) barley; 2) barley + copra; 3 ) maize; 4) maize + maize oil, in order to induce various degrees of lipid unsaturation in fat deposits. The proportion of saturated and unsaturated fatty acids were similar in the diets and in backfat deposits.

Diets had a large effect on the degree of fatty acid unsaturation; for example C18:2 content varied from 8 to $30 \%$, which is within the range usually noted in slaughter houses.

Two minced products were prepared using the backfat :1) a cooked product : hamburgers; 2) a dried product : dry sausages. 
Hamburger weight losses during cooking did not depend upon the nature of the fatty acids, but increased with hamburger fat content. However, sensory evaluation indicate that texture was softer and more tender when unsaturation increased.

Dry sausages prepared with the 4 types of fats presented a normal fermentation pattern (either homo or hetero) during processing. But drying of the sausages was mainly affected by the proportion of unsaturated fatty acids as can be seen from water activity curves. Sausages prepared with the most unsaturated fats could not reach a normal state of dryness and were not palatable.

It can be concluded that when the proportion of C18:2 is above $12-15 \%$ in the backfat, good quality dry products cannot be prepared.

Adipocyte and preadipocyte activity during genetic preobesity in the chicken. D. Hermier 1, B. Leclercq 1, A. Quignard-Boulange 2, M. Lafontan 3 (1 INRA, Nouzilly, 37380 Monnaie, 2 INSERM U177, 20, rue de l'Ecole-deMédecine, 75006 Paris and 3 INSERM U317, Institut de Physiologie, rue F.Magendie, 31400 Toulouse, France)

The storage capacity for plasma triglyceridederived fatty acids in abdominal adipose tissue has been investigated in 2 lines of chickens selected for either high or low fat content (fat line and lean line, respectively). Adipose tissue cellularity (cell size and number), and lipoprotein lipase (LPL) activity were estimated in 2 and 5 week old male birds. Cellularity and LPL activity at the onset of obesity (2 weeks), were evaluated in the stromal-vascular fraction (SVF) which contains adipocyte precursors. In addition, SVF cells were separated on a Percoll gradient according to their differentiation state, counted and the activities of the differentiation markers, LPL and glycerophosphate dehydrogenase (GPDH), determined. Susceptibility to lipolytic agents (glucagon, norepinephrine) was investigated in abdominal and subcutaneous adipose tissues.
At 2 and 5 weeks of age, the abdominal adipose tissue of the fat birds was characterized by a considerable hyperplasia with a 2fold increase in cell number and by a marked hypertrophia (30 and $20 \%$ increases in cell volume at 2 and 5 weeks of age, respectively), as compared to the lean line. In 2 week old birds, SVF cells were 2.5 -fold more numerous in the fat line, although relative cell distribution was similar in the 2 lines. LPL activity per cell was similar in lean and fat birds, irrespective of their age and nutritional state; however, total LPL activity in the whole abdominal fat pad was higher in fat birds at 5 weeks of age. Conversely, LPL activities were higher in all preadipocyte fractions from lean birds, while GPDH activity was unrelated to genotype.

Glucagon was a potent activator of lipolysis, and was more efficient on subcutaneous adipocytes that on abdominal tissue. $\alpha_{1}$ - and $B_{1}$-noradrenergic receptors were apparently absent in the chicken, whereas B2-receptors were numerous but insensitive to agonists normally used in mammals. However, there was no difference between the two lines.

Finally, the overdevelopment of adipose tissue in the fat line could not be related to an increase of LPL activity in adipocytes or to a decrease in their capacity of mobilizing lipids. The higher LPL activity in adipose tissue from fat birds resulted primarily from cell hyperplasia, which represents a major factor in the determination of adiposity in the chicken.

Biosynthesis and utilization of fatty acids in fat or lean chickens. $P$. Lemarchal and P. Legrand (Laboratoire de Biochimie, ENSA, 65, rue de Saint-Brieuc, 35000 Rennes, France)

These studies concern the two lines of chickens, fat (FL) and lean (LL), selected by Leclercq et al. (1980) (Br. Poultr. Sci. 21, 107113). They were carried out in an attempt to clarify the mechanism of lower deposition of abdominal fat in LL chickens during growth.

$\left[{ }^{14} \mathrm{C}\right]$ acetate was injected into 9 week old male chickens of both lines and its 